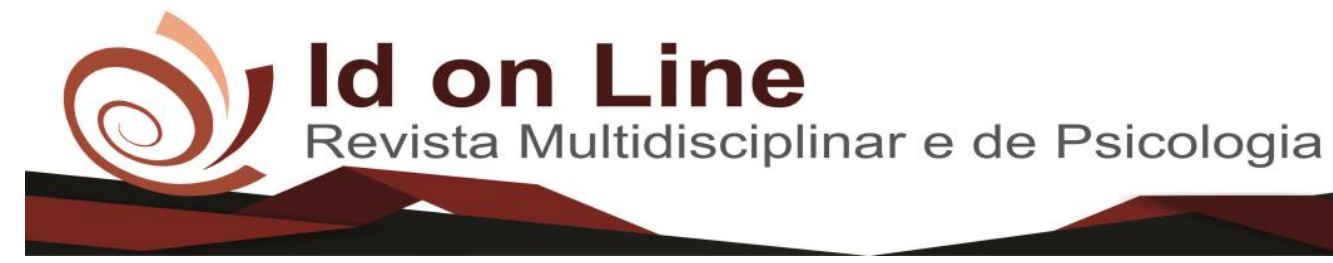

DOI: 10.14295/idonline.v15i55.3029

Artigo

\title{
25 anos da lei de Planejamento Familiar: Quais razões ainda limitam o amplo acesso a suas atribuições na Atenção Primária à Saúde?
}

\author{
Eclésio José Vascurado Chaves ${ }^{1}$; Milena Nunes Alves de Sousa ${ }^{2}$
}

\begin{abstract}
Resumo: Analisar na literatura disponível, o desenrolar de 25 anos de implementação da Política Nacional de Planejamento Familiar/Reprodutivo e suas consequências foi o objetivo do presente estudo. O que foidevidamente implementado, o que pode ser modificado, quais os desafios da política frente às novas construções relacionais do século 21. Métodos: Trata-se de uma RevisãoIntegrativa da Literatura, realizada durante os meses dezembro de 2020 e fevereiro de 2021, com análise de publicações indexadas em bases de dados, identificadas por meio de Descritores Controlados em Ciências da Saúde (DeCS), em língua portuguesa, artigosdisponíveis gratuitamente sem limitação e publicados entre os anos de 2015 e 2020. Resultados: Os estudos foram divididos em 5 tópicostema, enumerados em acordo comsua abordagem inserida na temática analisada: Educação em Saúde, Estruturação do Planejamento Familiar, Métodos Contraceptivos, Paradigmas eCapacitação/Conhecimento da equipe sobre a temática. Conclusão: O Sistema Único deSaúde (SUS), mais uma vez destaca-se como dos principais agentes promotores em saúdepública do planeta. A política reprodutiva é acometida de diversas falhas, sobretudo no sentido de não promover Educação em Saúde em seu sentido mais amplo. É visualizado também a importância da Estratégia de Saúde da Família, como porta de entrada do usuário a política e a necessidade de melhoria das estratégias em vista de o empoderar emdireção a um melhor aproveitamento de seus direitos sexuais e reprodutivos.
\end{abstract}

Descritores: Atenção Primária em Saúde e Planejamento Familiar.

\section{Years Of The Family Planning Law: What Reasons Still Limit The Broad Access To Its Attributions In Primary Health Care?}

\begin{abstract}
To analyze in the available literature, the development of 25 years ofimplementation of the National Policy for Family Planning/Reproductive Planning and its consequences was the objective of the present study. What has been properly implemented, what can be modified, what arethe policy challenges for the new relational constructions of the 21st century. Methods: This is an Integrative Review, carried out during the months of December 2020 to February 2021, with analysis of publications indexed in databases, identified through Controlled Descriptors in Health Sciences (DeCS), in Portuguese, articles freely availablewithout limitation and published between the years 2015 to 2020 . Results: The studies were divided into 5 theme topics, listed according to their approach inserted in the analyzed theme: Health Education, Structuring Family Planning, Contraceptive Methods, Paradigms and Training / Knowledge of the team on the theme. Conclusion: The UnifiedHealth System (SUS), once again stands out as one of the main promoters of public healthon the world. The reproductive policy is affected by several flaws, especially in the senseof not promoting Health Education to its fullest extent. The importance of the Family Health Strategy is also seen, as the user's gateway to politics and the need to improve strategies in order to empower them towards a better use of their sexual and reproductivehealth and rights.
\end{abstract}

Descriptors: Primary Health Care and Family Planning.

1 Médico Residente no Programa de Residência em Medicina de Família e Comunidade - UNIFIP/PB. eclesio@me.com; 2 Orientadora da produção científica. Doutorado e Pós-doutorado em Promoção de Saúde. Docente do Programade Residência em Medicina de Família e Comunidade - UNIFIP/PB 


\section{Introdução}

Dados da pesquisa "Nascer no Brasil”, coordenada pela Fundação Instituto Oswaldo Cruz(FIOCRUZ) em 2012, indicam que em um quantitativo superior a 23.000 mulheres puérperas no Brasil, 30\% alegavam não ter planejado a gestação atual; 9\% se mostraram insatisfeitas com a gravidez e 2,3\% relataram tentativa de interrupção da gestação. O panorama mostrado pela pesquisa, evidencia a necessidade de abordagem e consequentemelhoria das estratégias de Planejamento Familiar/Reprodutivo, em vistas de garantir a plenitude de Direitos e Saúde Sexual e Reprodutiva que fomentarão o exercício decisórionesse sentido ${ }^{1}$.

O planejamento familiar na qualidade de direito é descrito na Constituição de 1988, em seu artigo $226, \S 7^{\circ}$, no qual estabelece que o Estado deve propiciar recursos educacionaise científicos para garantir o pleno exercício desse direito reprodutivo ${ }^{2}$. Porém, somente em 1996 essa premissa constitucional foi regulamentada pela Lei n9.263/96 - A Lei do Planejamento Familiar - que passa a estabelecer conjunto de ações na Atenção Básica com vistas ao fomento de uma real vivência da sexualidade e da reprodução segura e saudável de mulheres e homens ${ }^{3}$.

Em 2010, a terminologia "Planejamento Familiar" foi modificada para "Planejamento Reprodutivo" no Caderno de Atenção Básica 26/2010 do Ministério da Saúde, em vistasa estabelecer nova definição, mais ampla, no sentido de que possa ser realizado pelo homem, pela mulher, por casais hétero e homoafetivos, tendo ou não o propósito de constituir família ${ }^{4}$.

Apesar dos avanços em 25 anos, as ações de Planejamento Reprodutivo ainda se baseiam em configuração unilateral, alicerçada em uma hierarquia de gênero, estabelecendo às mulheres a incumbência simbólica e corporal de contracepção, tendo como participação masculina somente a forma logística, preocupando-se apenas com o controle do número de filhos, desprezando o fato de o método ser aprazível ou não para o casal ${ }^{5}$.

Em corroboração ao versado na Carta Magna, o Planejamento Reprodutivo deve contemplar atividades educacionais, clínicas e de aconselhamento. Embora o planejamento reprodutivo seja de responsabilidade de todos os níveis de atenção, tal assistência deve ser oferecida principalmente na Atenção Primária à Saúde (APS), atravésda Estratégia Saúde da Família (ESF), entendida como porta de entrada do serviço de saúde, onde acontece o primeiro contato da família e da comunidade com Sistema Únicode Saúde (SUS) ${ }^{6}$.

Com tal aporte da Atenção Primária em Saúde, o saber torna-se ferramenta importante eeducação em saúde, passa nesse contexto a assumir importante papel norteador, na permuta de conhecimentos e vivências entre profissionais e usuários. Essa relação empodera os 
indivíduos a fazerem escolhas e tomarem decisões conscientes e embasadassobre seus direitos e saúde sexual e reprodutiva.

Apesar dessa relação tão íntima, educação em saúde e o trabalho em saúde ainda são colocadas em posições distintas no processo de fomento ao desenvolvimento de estratégias adequadas de Planejamento Reprodutivo em Atenção Primária em Saúde.

Dessa forma, esse estudo tem o objetivo de identificar falhas no processo de implantação de efetiva política de Planejamento Reprodutivo, bem como indicar estratégias bem- sucedidas no sentido de prover maior empoderamento sexual e reprodutivo ao usuário daAPS.

\section{Método}

O presente estudo é uma Revisão Integrativa da Literatura, definida como um método que proporciona a síntese de conhecimento e a incorporação da aplicabilidade de resultados de estudos significativos na prática ${ }^{7}$. Desta forma, o pesquisador pode elaborar uma revisão integrativa com diferentes finalidades, podendo ser direcionada para a definição de conceitos, revisão de teorias ou análise metodológica dos estudos incluídos de um tópico particular ${ }^{8}$.

Dessa forma, para aplicação do método, foi escolhida inicialmente a temática e, posteriormente, estabelecida a seguinte questão de pesquisa: 25 anos após a promulgaçãoda Lei do Planejamento Familiar, quais razões ainda limitam o amplo acesso a suas atribuições na Atenção Primária à Saúde?

Em sequência, foi empregada a seguinte estratégia de busca para seleção das produções científicas: Utilizados o operador booleano AND, considerando os DescritoresControlados em Ciências da Saúde (DeCS), em português: “Atenção Primária em Saúde" e "Planejamento familiar"; e em inglês "Primary healthcare" e "Family Planning". Foramutilizadas como bases de dados para busca, a Biblioteca Virtual em Saúde (BVS) e a Scientific Electronic Library Online (SciELO).

A filtragem precedeu os seguintes critérios de inclusão: Idioma em português e artigos publicados entre os anos de 2015 e 2020. Excluíram-se as repetições. Na tabela 1, é especificado o processo de busca pelas bases de dados, o cruzamento dos DeCS, quantidade de artigos identificados preliminarmente e os selecionados. 
Tabela 1: Caracterização de artigos quanto a base de dados, cruzamento de DeCS, quantidade de artigos identificados preliminarmente e artigos selecionados.

\begin{tabular}{|c|c|c|c|}
\hline $\begin{array}{c}\text { Base } \\
\text { de Dados }\end{array}$ & $\begin{array}{c}\text { Cruzamento } \\
\text { de DeCS }\end{array}$ & Identificados & Selecionados e títulos \\
\hline BVS & $\begin{array}{l}\text { "Atenção } \\
\text { Primária } \\
\text { em Saúde" } \\
\text { AND } \\
\text { "Planejamento } \\
\text { Familiar" }\end{array}$ & 34 & $\begin{array}{l}1 \text { - A percepção de agentes comunitárias de } \\
\text { saúde sobre o planejamento reprodutivo com } \\
\text { adolescentes. } \\
2 \text { - Atividades educativas do planejamento } \\
\text { reprodutivo sob a perspectiva do usuário da } \\
\text { atenção primária à saúde. } \\
3 \text { - Planejamento reprodutivo em casais } \\
\text { homossexuais na estratégia saúde da família. } \\
4 \text { - Ações de educação em saúde e o } \\
\text { planejamento familiar: um relato de } \\
\text { experiência. } \\
5-\text { A participação masculina no planejamento } \\
\text { familiar. } \\
6 \text { - Barreiras organizacionais para } \\
\text { disponibilização e inserção do dispositivo } \\
\text { intrauterino nos serviços de atenção básica à } \\
\text { saúde. } \\
7 \text { - Atenção em saúde no planejamento } \\
\text { reprodutivo: atitudes e práticas de enfermeiros. }\end{array}$ \\
\hline SciELO & $\begin{array}{c}\text { "Primary } \\
\text { Health Care" } \\
\text { AND } \\
\text { "Familiar } \\
\text { Planning" }\end{array}$ & 5 & $\begin{array}{l}1 \text { - Satisfaction with the use of contraceptive } \\
\text { methods among women from primary health } \\
\text { care services in the city of São Paulo, Brazil. } \\
2 \text { - Planejamento reprodutivo na clínica da } \\
\text { família de um Teias: condições facilitadoras e } \\
\text { limites à assistência. }\end{array}$ \\
\hline Total & & 39 & 9 \\
\hline
\end{tabular}

Fonte: Autoria própria, 2021.

Em posse dos artigos que perfazem a amostra, foi realizada sua leitura integral e, na ocasião, foram selecionadas as seguintes variáveis: base de dados, autores, ano, título, idioma e implicações. Concluiu-se a revisão, com a interpretação, análise e síntese dos resultados do material selecionado.

\section{Resultados}

A figura 1 traz os principais tópicos abordados com relação a aplicação do conceito de Planejamento Familiar a nível de Atenção Primária a Saúde. Dentre as temáticas abordadas, destacam-se: Educação em Saúde (33\% dos artigos), Estruturação do Planejamento Familiar 
(22\% dos artigos), Métodos Contraceptivos (11\% dos artigos), Paradigmas (22\% dos artigos) e Capacitação/Conhecimento da equipe (33\% dos artigos).Sendo que cada artigo pode abordar mais que uma temática.

Já a figura 2 estrutura os artigos selecionados nas temáticas abordadas e destacadas neste estudo.

Figura 1: Principais tópicos em Planejamento Familiar na APS

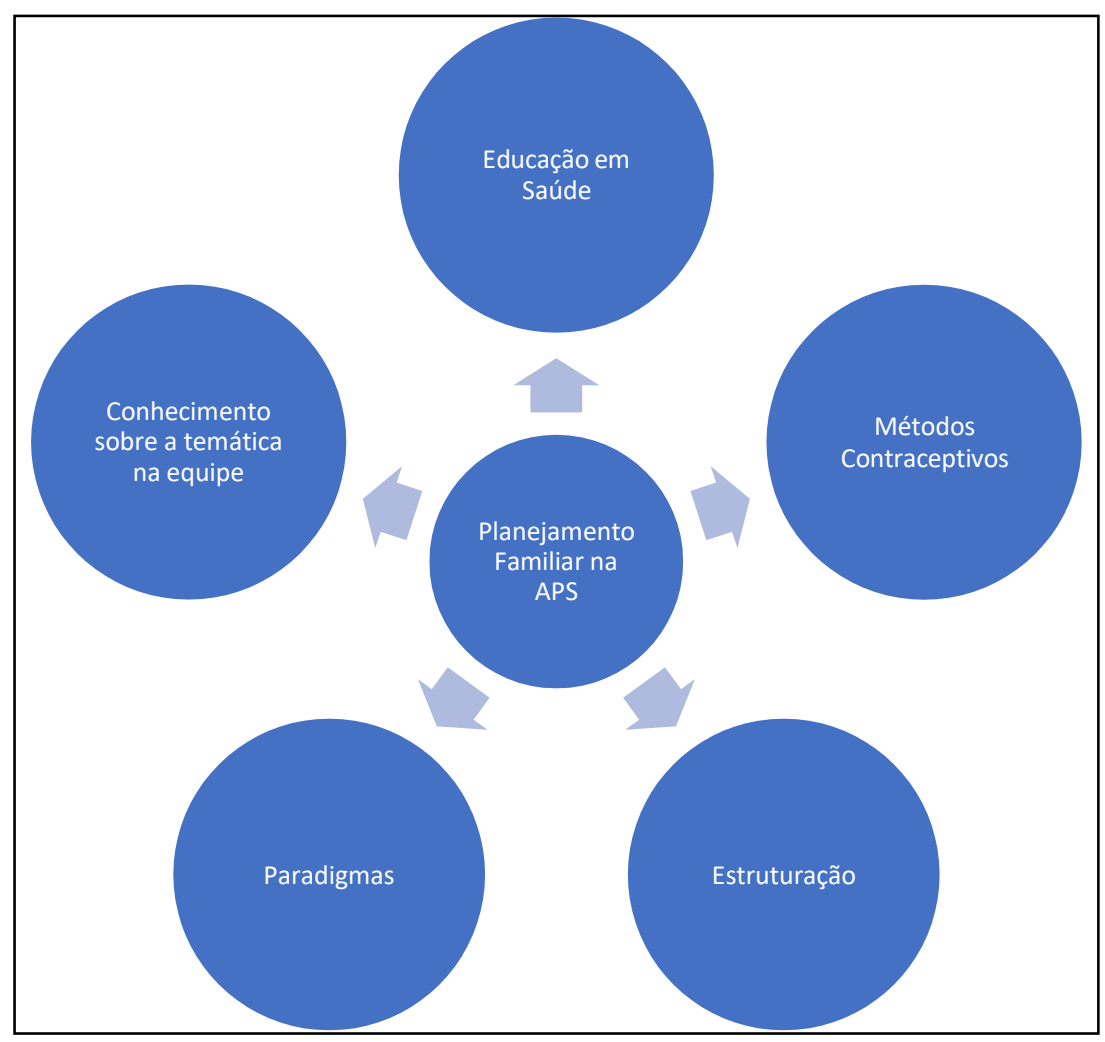

Fonte: Dados da Pesquisa, 2021.

Figura 2: Estruturação dos artigos selecionados sob estrutura de tópicosdestacados

\begin{tabular}{|c|c|c|c|c|}
\hline Educação em Saúde & $\begin{array}{c}\text { Métodos } \\
\text { Contraceptivos }\end{array}$ & Estruturação & Paradigmas & $\begin{array}{l}\text { Conhecimento sobre a } \\
\text { temática na equipe }\end{array}$ \\
\hline $\begin{array}{l}\text { - Costa et al. } \\
\text { - Paiva et al. } \\
\text { - Bezerra et al. }\end{array}$ & - Borges et al. & $\begin{array}{l}\text { - Gonzaga et al. } \\
\text { - Luiz et al. }\end{array}$ & $\begin{array}{l}\text { - Albuquerque et al. } \\
\text { - Dias et al. }\end{array}$ & $\begin{array}{l}\text { - Costa et al. } \\
\text { - Albuquerque et al. } \\
\text { - Almeida et al. }\end{array}$ \\
\hline
\end{tabular}

Fonte: Dados da Pesquisa, 2021. 


\section{Discussão}

A história do Planejamento familiar/Reprodutivo no Brasil remete aos idos do período colonial à república velha brasileira: Ações de incentivo ao natalismo, em vista do povoamento da nova terra foram dos primeiros lampejos, ainda que extraoficiais, que remetem ao planejamento reprodutivo brasileiro ${ }^{9}$. Embora não existisse uma política populacional clara, a tendência pró natalista era observada em várias leis que perduram até os dias atuais, como o salário-família, as leis de proteção da trabalhadora gestante, asdo auxílio-natalidade e auxíliomaternidade e a proibição do aborto ${ }^{10}$.

No contexto do pós-guerra, ganha força a chamada teoria Malthusiana em que se acreditava que a população cresceria em um ritmo acelerado comparado a uma progressão geométrica. Já a produção de alimentos cresceria de forma lenta, como numa progressão aritmética ${ }^{9}$. Neste contexto, exercendo sua posição de liderança entre as nações das Américas, os Estados Unidos criaram programas de controle populacionais a serem aplicados junto aos países latino-americanos e vinculados às ajudas econômicas ${ }^{9}$.

Desta maneira, ao mesmo tempo em que surgiram as medidas “controlistas" despontaram as ideias "anticontrolistas" baseadas nos avanços territoriais de países ricos sobre países ditos subordinados. No Brasil, as estratégias de saúde pública voltadas para o controle populacional do período colonial até meados do século XIX basearam-se no controle dosproblemas de natureza higienista, cabendo às juntas municipais a delegação das atribuições sanitárias ${ }^{11}$.

A grande problemática deste modelo dito liberalista, era a de que o mesmo focalizava apenas a mulher casada, isoladamente, como única responsável pelo processo de concepção, ignorando-se, por exemplo atividades sexuais extra-conjugais e outros elementos influenciadores de natureza cultural ou conflituosa que pudesse existir por trás do método anticoncepcional $^{12,13}$.

Somente com a retomada constitucional brasileira, por volta da década de 1980 , as mulheres passaram a fazer corpo e voz frente a direitos reprodutivos já consagrados internacionalmente: Ações como o PAISM, lançado em $1983^{14}$ deram embasamento ao início da divulgação ampla de ações voltadas ao planejamento familiar, que desembocariacom a garantia de tal direito na Carta Magna de 1988. Essas ações diferenciadas na saúde reprodutiva baseada na atenção integral à saúde superou as considerações sobreintenções de controle da natalidade, adotando a política de expandir o acesso da população aos meios de contracepção, todavia com informação e livre escolha ${ }^{15,16}$. 
Promulgada em 1989, a Constituição Federal de 1988, passa então a garantir através de seu art. $226, \S 7^{\circ}$ o direito ao planejamento familiar, como de livre escolha, com o devidoauxílio do estado de modo a propiciar condições técnico-científicas e financeiras para completo usufruto desse direito ${ }^{2}$.

Em 1996, a lei 9263, veio enfim ocupar a lacuna e regimentar os direitos garantidos pelo artigo constitucional de 8 anos antes ${ }^{3}$. Garantindo finalmente à mulher, ao homem ou aocasal, programa de atenção integral a saúde sexual e reprodutiva, incluindo em todo ciclovital da população, dentre outras, atividades básicas tais como assistência a concepção e contracepção, atendimento pré e pós-natal, controle de infecções sexualmente transmissíveis e ações voltadas ao provimento em educação em saúde da população ${ }^{3}$.

A problemática da implantação desse sistema de Planejamento Reprodutivo, de forma efetiva, então, perpassa questões não apenas estruturais, visto que ele deve incorporar valores de Educação em Saúde, abordagem clínica e aconselhamento ${ }^{3}$. Em estudos realizados após a implantação de tais políticas e analisados neste estudo, é relatado que usuários demonstram interesse em ações promovidas pela APS em planejamento reprodutivo, porém apontam série de fatores dificultadores para uma maior participação nas atividades facilitadas: ausência de maior gama de recursos visuais, não continuidadede atividades desenvolvidas e falta de clareza em comunicação entre as equipes e a população sobre ações de educação em saúde ${ }^{17}$.

Foram pontuadas questões de foro íntimo que acabam por interferir e limitar a vivência da saúde sexual e reprodutiva segura e saudável, apesar de saberem da importância da dupla função do preservativo, sobretudo mulheres relatam não o usarem por questão de confiança no parceiro ou pela união estável duradoura ${ }^{17}$. A vivência a nível de Atenção Primária à Saúde, mostra de fato que dentre os principais fatores que influenciam na vulnerabilidade às ISTs e gravidezes não planejadas, destacam-se aqueles ligados aos ritos da relação afetiva-sexual. Nesse contexto, cabe a reflexão acerca dos erros no processo ensino-aprendizado, como principal elemento transformador da chamada Educação em Saúde.

Definida pelo Ministério da Saúde como o conjunto de práticas que colaboram com a autonomia das pessoas no seu cuidado e no debate com profissionais e esferas governamentais, a fim de alcançar uma atenção em saúde de acordo com as demandas dos próprios usuários do sistema $^{18}$; a prática educativa em saúde é por definição o elemento norteador da população assistida no processo de escolhas conscientes e adaptadas as suas realidades. Entretanto, apesar de inerente ao trabalho desenvolvido a nível primário, a Educação em Saúde é colocada em segundo plano nas ações de cuidadoe sobretudo de gestão ${ }^{19}$. 
A política de planejamento reprodutivo ainda enfrenta dificuldade no acesso a capacitação das equipes ${ }^{11}$, sobretudo na elaboração de estratégias de abordagem de grupos de difícil penetrância, como é o caso dos adolescentes ${ }^{9}$. Apesar de relativamente recente, a política nacional de planejamento reprodutivo em certos momentos, parece estagnada frente às tecnologias, sobretudo comunicativas, incorporadas ao cotidiano e que poderiam ser elementos facilitadores na comunicação com tais grupos. Em estudo adicional, adolescentes relatam que apesar da proximidade com Agentes Comunitários deSaúde, o diálogo era dificultado pelo momento de a visita domiciliar ser em vista à presença dos pais; adicionalmente foi relatada que seria uma boa experiência o uso do aplicativo de mensagens de texto Whatsapp ${ }^{9}$. Apesar de tais experiências exitosas, essasainda não parecem fazer parte do cotidiano da estratégia de abordagem no planejamentoreprodutivo da maioria das unidades básicas de saúde.

A falta de uma abordagem em vistas a desconstrução de paradigmas e preconceitos, também é identificada como um fator limitante para o desenvolvimento pleno da equipe ${ }^{20}: \mathrm{A}$ abordagem de grupos, à época da criação da política de Planejamento Familiar, sobre uma ótica de construção familiar binomial e heteronormativa, acaba por ainda marginalizar grupos de construção reprodutiva diferentes à concepção prévia de uma sociedade com raízes fincadas no patriarcalismo, machismo e misoginia: A abordagem

do Planejamento Reprodutivo ainda com tais características, com a mulher assumindo o papel de única provedora de ações nesse sentido, dificulta ainda mais a ampliação geral das ações da política reprodutiva brasileira. Corroborando ainda nesse sentido, é listado adicionalmente em estudo avaliado, que homens citam fatores como vergonha, preconceito de amigos e medo de ostentar fragilidade perante seus iguais como os maioresobstáculos na busca por ações de controle da fecundidade ${ }^{21}$.

As ações a nível de Atenção Primária, devem encorajar homens, mulheres, adultos e adolescentes a se tornarem sujeitos capazes de promover o autocuidado, possibilitando o fortalecimento da autoestima, autodeterminação, para que possam exercer seus direitos sexuais e reprodutivos ${ }^{22}$. Retornamos nesse ponto, sobretudo ao fomento de uma melhorpolítica de Educação em Saúde, marcada sobretudo pelo ideal de construção de ideais napopulação e no profissional não ligados a pré-conceitos, mas a concepções fomentadas por resultados advindos da saúde baseada em evidências.

O alcance das ações em saúde sexual e reprodutiva deve ser amplo e adaptável a cada umdos públicos a que se refere: Postura, linguagem, forma e ambiente de comunicação são 
estratégias que se adaptadas, tendem a facilitar o acompanhamento do usuário a ações de planejamento e concepção familiar ${ }^{23}$.

A necessidade de desconstrução de ideais arraigados de preconceitos e solidificação de conhecimentos por parte das equipes de Atenção Primária à Saúde é um ponto que carecede uma análise adicional neste estudo: Saúde reprodutiva deve, definitivamente, ser política de estado, de modo a construções sociológicas não sejam afetadas por políticas de governos que justifiquem-se por ideais de conservadorismo, inações no sentido de prover ações e aprendizado amplo aos usuários do Sistema Único de Saúde. Essa atitudeé um ponto que claramente interferirá em uma melhor compreensão e desenvolvimento de uma visão longitudinal do tão abrangente e dinâmico conceito de Saúde Sexual e Reprodutiva, aqui analisado sob a ótica do Planejamento Reprodutivo ${ }^{17,20}$.

As opções contraceptivas oferecidas pelo SUS apesar de serem em bom número e variedade, sofrem com a ação de barreiras organizacionais relatadas pelos usuários do sistema: Erros de interpretação da lei nos critérios que dizem respeito a laqueadura tubária, critérios desnecessários para inserção de dispositivo intrauterino, ausência de profissionais com capacitação para realizar procedimentos de esterilização permanente, oferta insuficiente e muitas vezes descontinuada de determinados métodos - sobretudo com variação a políticas de governos nas esferas estaduais e municipais e finalmente a ausência de protocolos simplificados para opções contraceptivas de média complexidade ${ }^{24}$.

Tais barreiras devem ser revistas, de modo a facilitarem o acesso dos usuários a maior gama de opções contraceptivas: Métodos de fácil acesso, como o dispositivo intrauterino(DIU), seguem tendo dificuldades impostas sem respaldo científico ${ }^{24}$, laqueaduras tubárias e vasectomias seguindo protocolos diferentes do determinado pelo Ministério daSaúde (idade superior a 25 anos OU dois filhos vivos) e políticas reprodutivas ainda pautadas em assistencialismo.

É fundamental, portanto, para o sucesso desta estratégia que meros procedimentos burocráticos sejam pormenorizados, diretrizes sejam conhecidas e respeitadas ${ }^{24}$, que o

processo de capacitação da equipe, como ação de fomento a Educação em Saúde seja permanente $^{22}$ e que políticas de saúde reprodutiva sejam pautadas como direito constitucional ${ }^{2}$, em lugar de ações ligadas ou não a uma gestão ou outra.

Identificados ainda problemas de dimensão organizacional dos serviços de saúde e assistencial, entre eles, a irregularidade no fornecimento dos métodos, resultando na escassez e falta destes nas unidades de saúde, o que compromete a eficácia e a qualidadedas etapas do 
programa $^{25}$. Opções adicionais de contracepção, como o preservativo feminino, ainda se trata de opção pouco difundida nas unidades básicas de saúde, tanto pela ausência do método, quanto pela baixa procura ao mesmo; nesse aspecto é fundamental para ampliação a sua procura, a capacitação e sensibilização dos profissionais quanto ao uso da camisinha feminina.

Métodos contraceptivos, como a anticoncepção de emergência, enfrenta ainda obstáculosvindo no discurso de profissionais no qual assumem que um dos principais motivos paranão indicarem decorre do receio de que o seu uso se torne rotina ${ }^{26}$. O resultado da não difusão do método, mediada por valores profissionais que fogem aos princípios da saúde baseada em evidências, associado à falta de orientação ao usuário, leva ao uso do métodona grande maioria das vezes como automedicação.

É necessário a compreensão da Educação em Saúde como processo de aprendizado ao longo do tempo, como construção social: É evidenciado que quando as falhas mencionadas e notadas ao longo dos 25 anos de implementação da lei 9263/96 a nível dasUnidades Básicas de Saúde - admitidas aqui como porta de entrada ao sistema - são corrigidas, resultam em importante grau de satisfação do usuário do sistema, mesmo em decorrência, ainda de outros fatores fora do alcance das unidades de saúde ${ }^{27}$.

Por fim, vale a importante necessidade da identificação quanto as potencialidades e fragilidades da assistência ao planejamento reprodutivo ${ }^{28}$. As discussões sobre as estratégias de abordagem a população devem ser conduzidas de modo a abarcar as necessidades do usuário, pautadas no princípio constitucional da livre decisão, excluindovieses pessoais do profissional que conduzirá a clientela ao sistema. Um sistema que conhece suas peculiaridades, lida melhor com as adversidades em um trinômio em que ganha o profissional, o usuário e o Sistema Único de Saúde.

\section{Conclusão}

Nesse sentido, cabe a reflexão do papel da Atenção Básica como porta de entrada do usuário para o Sistema Único de Saúde (SUS) e é de total interesse do sistema, a qualificação da assistência a tal nível como forma de minorar os impactos em níveis maiselevados e, consequentemente mais custosos ao erário.

Tal qualificação do profissional, deve aprimorar a capacidade do mesmo em diferenciar concepções pessoais de instrumentos em saúde baseados em evidências, sendo esse segundo o 
real princípio norteador de suas ações na comunidade enquanto agente ativo da política nacional de planejamento reprodutivo.

A educação em saúde deve ser o principal instrumento de intervenção da atenção primária: Através dela se dará, inevitavelmente, a ampliação do conhecimento do usuárioacerca de seus direitos e, com isso, a plenitude de sua saúde sexual e reprodutiva.

Vale também a importante ressalva acerca da pouca quantidade de estudos publicados sobre tema de tamanha relevância: Embora os dados iniciais retornaram com 39 estudos,apenas 9 possuíam critérios que realmente se encaixavam na busca proposta. Este estudo,portanto, tem importante papel no sentido de levar a análise da implementação das políticas públicas em saúde reprodutiva, não devendo de forma alguma, ser único nesta missão.

Isso nos leva a recomendação acerca do fomento a condução de novos trabalhos sobre a temática. Outro ponto importante também a ser ressaltado, foi a ausência de experiências semelhantes em outros países, o que mais uma vez explana a posição vanguardista do Sistema Único de Saúde (SUS) como um dos principais agentes públicos promotores de saúde do planeta.

Desta forma, os fatos expostos nesta análise, demonstram que ainda existe um longo caminho a ser percorrido para a plena implementação dos direitos sexuais e reprodutivos,no que se refere a gestão do sistema, capacitação em saúde, implementação de políticas mais práticas e menos burocratizadas, quebra de paradigmas e preconceitos, mudança nas posturas profissionais, superação de deficiências visando a incorporação da integralidade,como princípio do Sistema Único de Saúde.

A Estratégia Saúde da Família aproxima os sujeitos, ampliando a compreensão de suas idiossincrasias. É nesse nível sobretudo, que deve se basear a assistência ao planejamento reprodutivo; em vistas do empoderamento do usuário em prol de um completo usufruto de seus direitos sexuais e reprodutivos, minoração de barreiras organizacionais e quebra de preconceitos e paradigmas rumo a plenitude.

\section{Referências}

1. Vasconcellos MTL, Silva PLN, Pereira APE, Schilithz AOC, Souza JPRB,Szwarcwald CL. Desenho da amostra Nascer no Brasil: Pesquisa Nacional sobreParto e Nascimento. Cad. Saúde Pública. 2014; 30(1):49-58.

2. Brasil. Constituição Federal. República Federativa do Brasil 1988.

3. Brasil. Lei n. 9.263 de 12 de janeiro 1996. Regula o $\S 7^{\circ}$ do Art. 226 daConstituição 
Federal, que trata do planejamento familiar, estabelece penalidades e dá outras providências. Diário Oficial da União. 12 jan 1996.

4. Brasil. Ministério da Saúde. Secretaria de Atenção à Saúde. Departamento de Atenção Básica. Saúde sexual e saúde reprodutiva. Ministério da Saúde, Secretaria de Atenção à Saúde, Departamento de Atenção Básica. Brasília: Ministério da Saúde, 2013.

5. MORAES ACB et al. Participação masculina no planejamento familiar e seus fatores intervenientes. Revista de enfermagem UFSM, v. 4, n. 3, p. 498-508, jul/set. 2014.

6. Brasil. Ministério da Saúde. Norma Operacional da Assistência à Saúde - NOASSUS 01/2001. Brasília; 2001.

7. Souza MT, Silva MD, Carvalho R. Revisão integrativa: o que é e como fazer. Einstein (São Paulo). 2010;8(1):102-6. https://doi.org/10.1590/s1679- 45082010rw1134.

8. Ercole FF, Melo LS, Alcoforado CLGC. Revisão integrativa versus revisão sistemática. Revista Mineira de Enfermagem, v. 18.1. 2014 jan/mar; 18(1): 1-260.

9. Costa A, Rosado L, Florêncio A, Xavier E. História do planejamento familiar e sua relação com os métodos contraceptivos. Revista Baiana de Saúde Pública. v.37, n.1, p.7486jan./mar. 2013.

10. DICIONÁRIO DE ECONOMIA, São Paulo, Abril cultural, 1985.

11. Barreto FSC. A bioética da proteção e o programa de assistência ao planejamentofamiliar: a percepção das usuárias e profissionais dos ambulatórios e maternidadesde Teresina-PI [Dissertação]. Brasília: Universidade de Brasília; 2010.

12. Barroso C. Esterilização feminina: liberdade e opressão. Rev saúde pública. 1984;18(2):170-80.

Extraído

de [http:www.scielosp.org/scielo.php?script=sci_arttext\&pid=S003489101984000200009\&lng=en\&nrm=iso], acesso em [5 de março de 2021].

13. Uma vida só (Pare de tomar a pílula) (Odair José - Ana Maria). Gravação de OdairJosé. LP “Odair José”. Polydor. P. 1973.

14. BRASIL, Ministério da Saúde. Assistência Integral à Saúde da Mulher: bases deação programática. Brasília, 1984. Disponível em: http://bvsms.saude.gov.br/bvs/publicacoes/assistencia_integral_saude_mulher.p df. Acesso em: 05 mar. 2021.

15. Silva RM, Araújo KNC, Bastos LAC, Moura ERF. Planejamento familiar: significado para mulheres em idade reprodutiva. Ciênc saúde coletiva. 2011;16(5):2415-24. Extraído

de [http://www.redalyc.org/pdf/630/63018749010.pdf], acesso em [05 de março de 2021].

16. Paz ECM, Ditterich RG. O conhecimento das mulheres sobre os métodos contraceptivos no planejamento familiar. Rev gestão \& saúde.2009;1(1):1-10.

Extraído de [http://www.herrero.com.br/revista/Edicao\%201\%20Artigo\%204.pdf], acesso em [5 de março de 2021].

17. Paiva CCN, Caetano R, Saldanha BL, Penna LHG, Lemos A. Atividades educativas do planejamento reprodutivo sob a perspectiva do usuário da Atenção Primária à Saúde. Revista de APS. 2019. 22. 23-46. 10.34019/1809-8363. 2019. v22.16675.

18. Brasil. Ministério da Saúde. Secretaria de Atenção à Saúde. Departamento de Atenção Básica. Política Nacional de Atenção Básica. 4. ed. Brasília: Ministério da Saúde; 2006. $68 \mathrm{p}$.

19. Falkenberg MB, Mendes TPL, Moraes EP, Souza EM. Educação em saúde e educação na 
saúde: conceitos e implicações para a saúde coletiva. Ciênc. Saúde Coletiva. 2014;19 (3): 847-852.

20. Albuquerque GA, Belém JM, Nunes JFC, Leite MF, Quirino GS. Planejamento reprodutivo em casais homossexuais na estratégia saúde da família. Rev. APS. 2018 jan/mar; 21(1): $104-111$.

21. Dias MG et al. A participação masculina no planejamento familiar. HU Revista, Juiz de Fora, out./dez. 2017. v. 43, n. 4, p. 349-354.

22. Bezerra INM et al. Ações de educação em saúde e o planejamento familiar: um relato de experiência. Revista Ciência Plural.2018;4(3):82-90.

23. Costa CC, Silva CD, Acosta DF, Gutmann VLR. A percepção de agentes comunitárias de saúde sobre o planejamento reprodutivo com adolescentes. Rev.Enferm. UFSM. 2020 [Acesso em: 2020 November 10]; vol.10 e57: 1-15. DOI:https://doi.org/10.5902/2179769240345.

24. Gonzaga VAS, Borges ALV, Santos AO, Santa Rosa PLF, Gonçalves RFS. Organizational barriers to the availability and insertion of intrauterine devices in Primary Health Care Services. Rev Esc Enferm USP. 2017;51:e03270. DOI: http://dx.doi.org/10.1590/S1980$220 X 2016046803270$.

25. Almeida MP et al. Atenção em saúde no planejamento reprodutivo: atitudes e práticas de Enfermeiros. Rev Enferm UFSM 2016 abr./Jun.;6(2): 270-280.

26. Spinelli MBAS, Souza AI, Vanderlei LCM, Vidal SA. Características da oferta de contracepção de emergência na rede básica de saúde do Recife, Nordeste do Brasil. Saúde Soc. 2014;23(1):227-37.

27. Borges ALV et al. Satisfaction with the use of contraceptive methods amongwomen from primary health care services in the city of São Paulo, Brazil. Rev.Bras. Saude Mater. Infant. [Internet]. 2017 Dec [cited 2021 Jan 02] ; 17( 4 ):749-756. Available from:

http://www.scielo.br/scielo.php?script=sci_arttext\&pid=S1519-

38292017000400749\&lng=en. https://doi.org/10.1590/1806-93042017000400008.

28. Luiz MS, Nakano AR, Bonan C. Planejamento reprodutivo na clínica da família de um Teias: condições facilitadoras e limites à assistência. Saúde debate 39 (106)Jul-Sep 2015. https://doi.org/10.1590/0103-110420151060003009.

\section{Como citar este Artigo (ABNT):}

CHAVES, Eclésio José Vascurado; SOUSA, Milena Nunes Alves de. 25 anos da lei de Planejamento Familiar: Quais razões ainda limitam o amplo acesso a suas atribuições na Atenção Primária à Saúde?. Id on Line Rev.Mult. Psic., maio/2021, vol.15, n.55, p. 20-32. ISSN: 1981-1179.

Recebido: 03/03/2021;

Aceito: 8/03/2021. 